Gut, 1971, 12, 1-10

\title{
Studies of colonic carcinoma antigens
}

\author{
MARTIN S. KLEINMAN, ${ }^{1}$ LEE HARWELL, AND MICHAEL D. TURNER \\ From the Isaac Gordon Laboratory for Gastrointestinal Research, University of Rochester \\ School of Medicine and Dentistry, Rochester, New York 14620, USA
}

SUMMARY Extracts of human colonic adenocarcinomata were made with perchloric acid and shown to contain antigens which were not present in pooled samples of normal colonic mucosa or in healthy colonic mucosa from patients providing the tumours. Antisera prepared against the tumour extracts gave two precipitin lines on immunodiffusion, and antiserum prepared in Montreal according to the methods devised by Gold and Freedman (1965a and b) also gave two lines of precipitation when tested against some of these extracts; one of these precipitin lines gave a reaction of identity with that given by the antiserum produced here. The results suggest that perchloric acid may extract two antigens from colonic carcinomata.

The exciting possibility of the development of a widely applicable and simple immunological screening technique for the detection of gastrointestinal carcinoma has been raised by the investigations of Gold and Freedman (1965a and 1965b) and colleagues (Thomson, Krupey, Freedman, and Gold, 1970). They have found that dilute perchloric acid will extract antigens from human colonic carcinoma which are not found in the normal adult colonic mucosa. Antigenic similarities between these materials and foetal entodermal tissue led Gold and Freedman (1965b) to name them 'carcinoembryonic antigens of the digestive tract' (CEA). Von Kleist and Burtin (1969) recently demonstrated the presence of a number of antigens in colonic carcinoma and human foetal tissue which are not found in normal adult colonic mucosa. They thought that some of their antigens were similar or identical to the CEA of Gold and Freedman (1965b) but did no studies which compared the reaction of their sera with those produced by Gold. Yachi, Matsuura, Carpentier, and Hyde (1968) have also reported the occurrence of an antigen in gastric and colonic tumours which is insoluble in perchloric acid.

This report describes the extraction and partial purification of antigenic materials from human colonic carcinoma and the production of absorbed rabbit antisera against them. These sera when

1Advanced clinical fellow of the American Cancer Society.
Received for publication 21 September 1970. studied by double diffusion in agar gel (Ouchterlony, 1949) gave precipitin lines against extracts of colonic carcinoma which could not be removed by absorption with extracts of normal adult colon tissue, normal human plasma, or colonic bacteria but when tested with a serum prepared by $\mathrm{Dr}$ Gold in Montreal a line of identity was observed. Observations were made which suggest that heterogeneity exists within this antigen-antibody system.

\section{Materials}

Freund's complete adjuvant and Noble agar were supplied by Difco Laboratories, Detroit, Michigan. Ampholyte carriers and the apparatus for immunoelectrophoresis and the electrofocusing equipment were manufactured by LKB Producter AB, Sweden. The direct current power supply was a voltage regulated model $800 \mathrm{~B}$ made by Kepco Inc. of Flushing, New York. G200 Sephadex was obtained from Sigma Chemical Company, St. Louis, Missouri, Pevikon from the Mercer Chemical Corporation, New York, and microgranular DE 32 diethylaminoethyl-cellulose from W. R. Balston, Ltd, England. Goat anti-rabbit immunoglobulin $\mathrm{G}$ and anti-rabbit whole serum were obtained from Hyland Laboratories. The Diaflo ultrafiltration cell was supplied by the Amicon Corporation, Lexington, Massachusetts, and Millipore filters made of cellulose ester by Millipore Corporation, Bedford, Massachusetts. 
Phosphate-buffered saline, $p \mathbf{H} 7 \cdot 3$, was made up by mixing $173.5 \mathrm{~g} \mathrm{Na}_{2} \mathrm{HPO}_{4}$ with $37.9 \mathrm{~g}$ $\mathrm{KH}_{2} \mathrm{PO}_{4}$ and $87.7 \mathrm{~g} \mathrm{NaCl}$ and making up to 20 litres with water. $0.01 \mathrm{M}$ Borate buffer, $p \mathbf{H} 8 \cdot 6$, was made up by mixing $12.4 \mathrm{~g} \mathrm{H}_{3} \mathrm{BO}_{4}$ and $14.9 \mathrm{~g}$ $\mathrm{KCl}$ with $2,400 \mathrm{ml}$ of $0.02 \mathrm{M} \mathrm{NaOH}$ and making

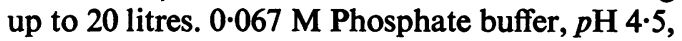
was made up by mixing $0.067 \mathrm{M} \mathrm{Na}_{2} \mathrm{HPO}_{4}$ with $0.067 \mathrm{M}$. $\mathrm{KH}_{2} \mathrm{PO}_{4}$ and adjusting the $p \mathrm{H}$ with $0.067 \mathrm{M} \mathrm{H}_{3} \mathrm{PO}_{4}$.

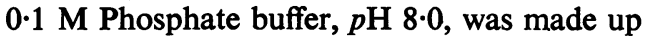
by taking $1.72 \mathrm{~g} \mathrm{KH}_{2} \mathrm{PO}_{4}$ and $1.39 \mathrm{~g} \mathrm{Na}_{2} \mathrm{HPO}_{4}$ and making up to 4 litres with water. $0.05 \mathrm{M}$ Phosphate buffer, $p \mathrm{H} 6 \cdot 3$, was made up by taking $20.86 \mathrm{~g}$ of $\mathrm{KH}_{2} \mathrm{PO}_{4}$ and $6.43 \mathrm{~g}$ of $\mathrm{Na}_{2} \mathrm{HPO}_{4}$ and making up to 4 litres with water. 0.03 M Barbital buffer, $p \mathrm{H} 8.3$, was made up by taking $80.5 \mathrm{~g}$ of sodium barbital and $38.6 \mathrm{~g}$ of diethylbarbituric acid and making up to 20 litres with water.

\section{Methods}

Extracts were prepared after the method of Gold and Freedman (1965a) with some modifications. A large number of colonic carcinomata removed at surgery were frozen at $-20^{\circ} \mathrm{C}$ and stored until used. One hundred and sixty-five $\mathrm{g}$ of tumour was thawed and suspended in $330 \mathrm{ml}$ of distilled water. The suspension was homogenized at half maximum speed in a Virtis $\mathbf{4 5}$ homogenizer for one hour at $0^{\circ} \mathrm{C}$. This suspension was mixed with an equal volume of $1.2 \mathrm{M}$ perchloric acid and stirred at room temperature for 10 minutes. It was then homogenized in a loose Potter-Elvehjem homogenizer and subsequently stirred at room temperature for an additional 20 minutes. After centrifugation at $2,650 \times g$ at $4^{\circ} \mathrm{C}$ for 15 minutes, the supernatant was removed and put aside. The sediment was resuspended in twice its volume of distilled water and an equal volume of $1.2 \mathrm{M}$ perchloric acid added. This mixture was stirred at room temperature for 30 minutes and recentrifuged as above. The precipitate was discarded. The two supernatants were combined and dialysed for 24 hours against cold running tap water at $4^{\circ} \mathrm{C}$. The dialysis residue was concentrated to one fifth of its volume in a Diaflo ultrafiltration cell using a UM $1(10,000$ molecular weight) membrane and centrifuged at 10,500 $\times g$ at $4^{\circ} \mathrm{C}$ for 30 minutes. The clear supernatant was sterilized by passing it through a $0 \cdot 22 \mu$ Millipore filter and lyophilized. This final material was termed 'perchlorate extract of colonic carcinoma'. Extracts were made in a similar manner from normal human colonic mucosa obtained at necropsy within 12 hours of death from patients who had died from non-neoplastic diseases, and from normal colonic mucosa from subjects bearing tumours. Such mucosa was always taken at more than $7 \mathrm{~cm}$ from any visible tumour.

\section{PEVIKON ELECTROPHORESIS}

Two hundred and ten $\mathrm{g}$ of Pevikon was mixed with $120 \mathrm{ml}$ of $0.01 \mathrm{M}$ borate buffer, $p \mathrm{H} \mathrm{8.6}$, and formed into a block $10 \times 30 \times 1 \mathrm{~cm}$. A trough $1 \times 8 \mathrm{~cm}$ was cut $8 \mathrm{~cm}$ from the cathodal end. Seventy-five mg of lyophilized perchlorate extract of colonic carcinoma was dissolved in $3 \mathrm{ml}$ of

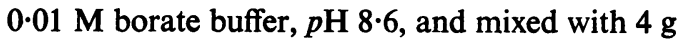
of dry Pevikon which was then used to fill the trough. After electrophoresis at $400-500 \mathrm{~V}$ and $18 \mathrm{~mA}$ for 14 hours the block was cut into fractions of $1 \mathrm{~cm}$ which were eluted with phosphatebuffered saline, $p H \mathbf{H} 7 \cdot 3$. Each fraction was then assayed for CEA using Ouchterlony plates and rabbit anti-CEA absorbed with normal human tissue as described below. The highest concentration of CEA was found $7 \mathrm{~cm}$ from the origin while most of the protein was at $15 \mathrm{~cm}$. The fractions containing CEA were pooled, dialysed against four changes of distilled water for 24 hours at $4^{\circ} \mathrm{C}$, centrifuged at $43,500 \times g$ at $4^{\circ} \mathrm{C}$ for 30 minutes, and passed through a $0.22 \mu$ Millipore filter. This material was then lyophilized. This preparation was termed 'Pevikon separated CEA'.

\section{SEPHADEX G200 GEL FILTRATION}

A column, $100 \times 5 \mathrm{~cm}$, was packed with Sephadex G200 in 0.067 M phosphate buffer, $p \mathrm{H} 4 \cdot 5$, in the usual manner (Flodin, 1962). It was then eluted in a downward direction under gravity at a flow rate of $60 \mathrm{ml}$ per hour. The eluate was collected in fractions of $20 \mathrm{ml}$. The void volume of the column was determined with blue dextran, which first appeared in fraction 22. Pevikonseparated CEA $(0 \cdot 1 \mathrm{~g})$ was dissoved in $5 \mathrm{ml}$ of the same buffer and placed on the column. The fractions were assayed for the presence of CEA using Ouchterlony plates and absorbed rabbit anti-CEA. Fractions containing CEA were dialysed against distilled water for 24 hours at $4^{\circ} \mathrm{C}$ and passed through a $0 \cdot 22 \mu$ Millipore filter before lyophilization.

\section{ELECTROFOCUSING OF CEA}

An LKB 8100 electrofocusing column of $110 \mathrm{ml}$ volume was employed to purify further the material collected from the G200 Sephadex column. The anode chamber was placed at the 
bottom of the column and filled with $20 \mathrm{ml}$ of a solution containing $0.2 \mathrm{ml}$ of concentrated $\mathrm{H}_{3} \mathrm{PO}_{4}$ in $70 \%$ glycerol. Seven $\mathrm{mg}$ of the material obtained from the gel filtration of Pevikonseparated CEA was dissolved in $47 \mathrm{ml}$ of a light

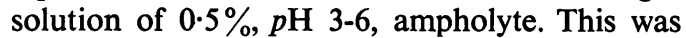
used to form a density gradient in the focusing column by mixing it with $47 \mathrm{ml}$ of a dense solution of $1.26 \%$ ampholyte in $50 \%$ glycerol $(\mathrm{w} / \mathrm{v})$ using an LKB gradient generator. The cathode at the top of the column contained $2 \%$ aqueous ethanolamine. Focusing was achieved by electrophoresis at 500 volts for 72 hours at $3^{\circ} \mathrm{C}$. Each fraction was tested for the presence of CEA and its $p \mathrm{H}$ measured before dialysis against distilled water at $4^{\circ} \mathrm{C}$ for 96 hours. After removal of the ampholyte by dialysis the protein content of the fractions was determined by the method of Lowry, Rosebrough, Farr, and Randall (1951). Fractions containing CEA were centrifuged at $43,500 \times g$ at $4^{\circ} \mathrm{C}$ for 30 minutes and then passed through a $0 \cdot 22 \mu$ Millipore filter before lyophilization.

\section{PREPARATION OF ANTI-CEA SERUM}

Six male New Zealand white rabbits $(2 \cdot 5 \mathrm{~kg})$ were immunized with a mixture of perchlorate extract of colonic carcinoma in Freund's complete adjuvant. Each animal was immunized twice weekly for four weeks. Each immunization consisted of $1.2 \mathrm{ml}$ of material made by mixing $0.6 \mathrm{ml}$ of Freund's complete adjuvant with an equal volume of a solution of perchlorate extract of colonic carcinoma containing $3.0 \mathrm{mg}$ of protein as determined by the Lowry procedure (Lowry et al, 1951). The material was emulsified with a size 20 emulsifying needle and $0.2 \mathrm{ml}$ was injected between each pair of digits on a single foot pad and an additional $0.4 \mathrm{ml}$ was injected subcutaneously into the flank. These sites of injection were rotated over a period of one month. Blood was drawn by arterial puncture from the fortysecond day after the start of immunization.

\section{ABSORPTION OF ANTI-CEA SERUM}

Human AB Rh-positive red cells were obtained from the blood bank and washed three times in buffered saline. The rabbit anti-CEA serum from a single animal was mixed with an equal volume of washed AB Rh-positive red cells. The mixture was placed in the cold at $4^{\circ} \mathrm{C}$ for two hours and then centrifuged at $23,000 \times g$ at $4^{\circ} \mathrm{C}$ for 30 minutes. The supernatant material was removed and reabsorbed in a similar manner with two further aliquots of AB Rh-positive red cells.

Normal human colonic mucosa, obtained from operation or necropsy specimens, was scraped off and suspended in distilled water $(4 \mathrm{ml} / \mathrm{g}$ wet tissue). This mixture was then homogenized for 15 minutes at maximum speed in the Virtis 45 homogenizer at $4^{\circ} \mathrm{C}$. The homogenate was centrifuged at $4,000 \mathrm{~g}$ at $4^{\circ} \mathrm{C}$ for 15 minutes and the sediment discarded. Streptomycin sulphate $(15 \mu \mathrm{g})$ was added to each ml of supernatant which was mixed well and lyophilized. Pooled normal human plasma from subjects of all $\mathrm{ABO}$ blood groups was dialysed against distilled water and lyophilized.

Lyophilized pooled normal human colon powder $(0.5 \mathrm{~g})$ and $0.5 \mathrm{~g}$ of normal human serum were added to $50 \mathrm{ml}$ rabbit anti-CEA serum after it had been absorbed with red cells. The precipitate formed in 12 hours at $4^{\circ} \mathrm{C}$ was removed by centrifugation and the absorbed serum tested by double diffusion against extracts of normal colon, colonic cancer, and normal plasma. In most instances it was found that these quantities of normal serum and of colon powder were sufficient to absorb all antibodies against the antigens from normal tissues. However, if the sera showed residual precipitins to normal tissue antigens they were submitted to further absorption until these had been eliminated.

\section{DEAE-CELLULOSE CHROMATOGRAPHY}

The absorbed rabbit anti-CEA serum was submitted to chromatography on DEAE-cellulose to obtain rabbit IgG with anti-CEA activity. One hundred and thirty $g$ of DE 32 microgranular DEAE-cellulose was precycled according to the manufacturer's recommendations with acid and alkali. After suspension the material was titrated to $p \mathrm{H} \mathrm{8.0}$ with concentrated $\mathrm{H}_{3} \mathrm{PO}_{4}$ and allowed to stand overnight. It was then resuspended each day for one week in fresh $0.01 \mathrm{M}$ phosphate buffer, $p \mathrm{H} \mathrm{8 \cdot 0}$. The DEAE-cellulose was packed into a column, $2.5 \times 10 \mathrm{~cm}$, by gravity and washed for one week at $4^{\circ} \mathrm{C}$ with the same buffer. Five $\mathrm{ml}$ of absorbed anti-CEA serum was dialysed overnight

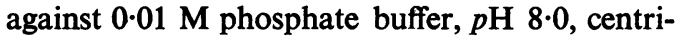
fuged at $13,300 \times g$ at $4^{\circ} \mathrm{C}$ for 20 minutes, and immediately loaded on to the column. The serum was allowed to flow gently into the bed of DEAEcellulose through an upper layer of fine glass beads. A layer of fresh buffer was then placed on the column to a point some $3 \mathrm{~cm}$ above the beads. Elution was begun with the same buffer and fractions were collected, beginning at the point at which the serum was first allowed to enter the column. Fractions of $14.5 \mathrm{ml}$ were collected at a rate of one fraction per hour. The extinction of the fractions at $280 \mathrm{nM}$ was measured in a spectro- 
photometer and antibody activity was detected by double diffusion against various preparations of CEA. Two peaks of material absorbing at $280 \mathrm{nM}$ were detected in the eluate obtained with the initial 0.01 M phosphate buffer. Following the elution of these materials the column was washed sequentially with $300 \mathrm{ml}$ of $0.02 \mathrm{M}$ phosphate buffer, $p \mathrm{H} 6.0$, and $300 \mathrm{ml}$ of $0.5 \mathrm{M}$ phosphate buffer, $p \mathrm{H} 6 \cdot 3$.

\section{IMMUNODIFFUSION}

The Ouchterlony double-diffusion technique (1949) was used to determine the presence of antibody activity. Noble agar was prepared in $0 \cdot 15 \mathrm{M}$ phosphate buffer, $p \mathrm{H} 7 \cdot 3$. Sufficient $0.85 \%$ agar was poured into a Petri dish to give a layer $2 \mathrm{~mm}$ thick. Wells were cut in the agar with a special punch designed to give a single centre well of $8 \mathrm{~mm}$ diameter surrounded by a ring of six
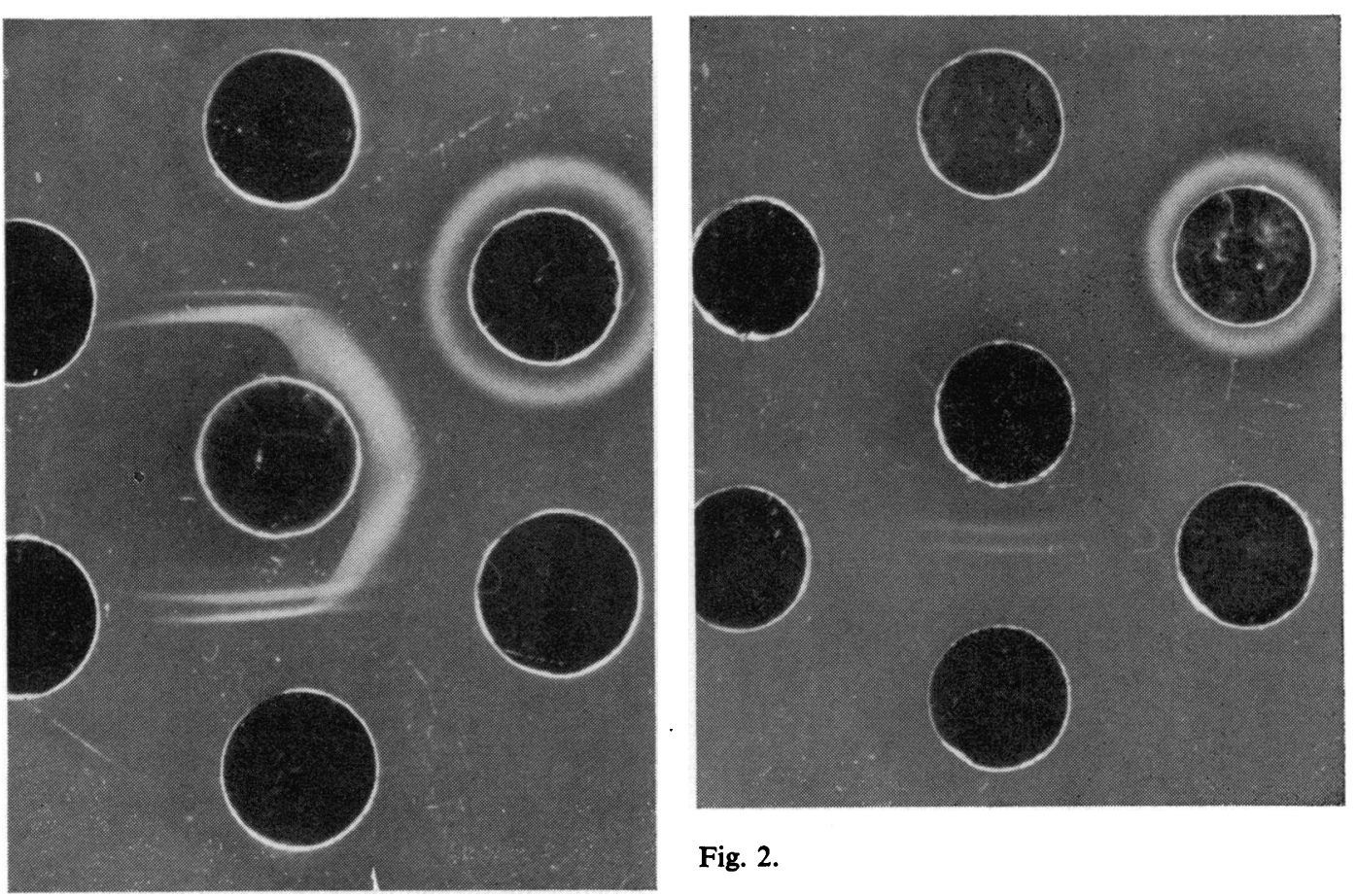

Fig. 2.

evenly spaced wells of the same diameter. The centre of each of the surrounding wells was 15 $\mathrm{mm}$ from the centre well. Each well held about $0.1 \mathrm{ml}$ of material. For immunodiffusion the wells were filled with the specimens to be evaluated and the dishes incubated in a chamber saturated with water vapour for 18 hours at $37^{\circ} \mathrm{C}$. They were then kept in a moist chamber at room temperature. The unfixed plates were photographed at intervals using dark-ground illumination in the immunodiffusion camera.

\section{IMMUNOELECTROPHORESIS}

Immunoelectrophoresis was carried out on Swedish microscope slides in $0.03 \mathrm{M}$ barbital buffer, $p \mathrm{H} 8 \cdot 3$, containing $1.5 \%$ Noble agar. Fractions of gamma globulin from the DEAEcellulose column were electrophoresed for one and a half hours at 300 V. Goat anti-whole-

Fig. 1. Centre well contains unabsorbed rabbit serum from an animal immunized against perchlorate extract of human colonic carcinoma. Note the precipitin lines against pooled normal human colon extract (well 1), pooled normal human serum (well 2), pooled normal human plasma (well 3), and perchlorate extract of colonic carcinoma (well 4). (The wells are numbered clockwise from the top centre.)

Fig. 2. Eighteen-hour immunodiffusion plate. Centre well contains serum from a rabbit immunized against perchlorate extract of colonic carcinoma after absorption with pooled human red cells, pooled human plasma, and pooled normal colon extract. Note that two precipitin lines are now observed against the extract of colonic carcinoma (well 4) but that no lines appear against normal human colon (well 1), human serum (well 2), and human plasma (well 3) (cf Fig. 1). 
rabbit serum was then placed in the troughs and diffusion continued for 18 hours. The resulting precipitin patterns were photographed with the immunodiffusion camera, using darkground illumination.

\section{Results}

Sera collected from rabbits from the forty-second day after the start of the course of immunization gave numerous precipitin lines against extracts of normal human colon, colonic carcinoma, and normal human serum (Fig. 1). However, after absorption with red cells, lyophilized human colon powder, and normal human plasma no precipitin lines could be detected on immunodiffusion against normal human plasma, serum, or colon, while two distinct precipitin lines were observed against the perchlorate extract of colonic carcinoma (Fig. 2).

Two types of experiment were conducted to confirm that neither of these precipitin arcs

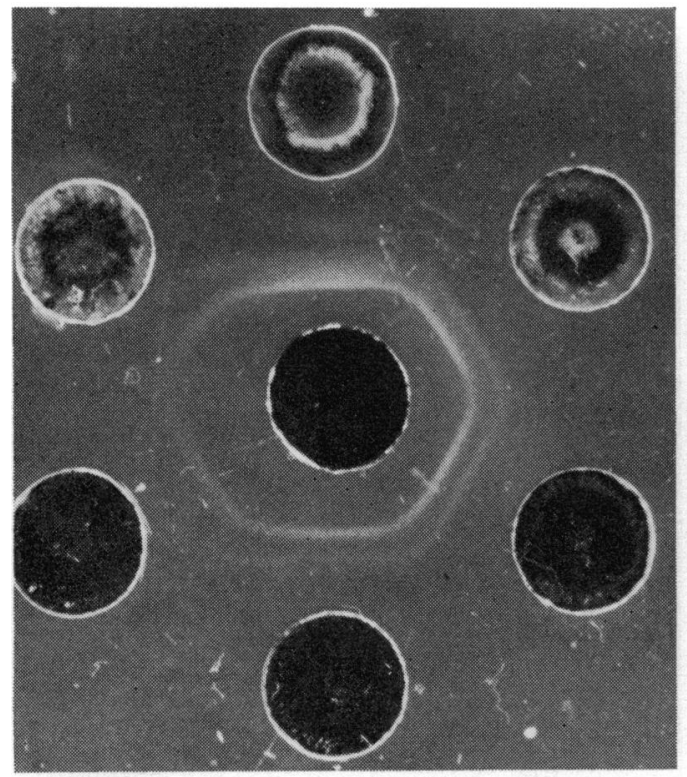

Fig. 3a. represented a reaction of antibodies with normal tissue components. In the first, doubling dilutions of the absorbed antiserum were made in an extract of pooled normal human colonic mucosa $(5 \mathrm{mg}$ powder $/ \mathrm{ml}$ ), and used to fill the outer wells of an immunodiffusion plate, the centre well containing the tumour extract. A control was set up in which the antiserum was serially diluted in buffered saline. After diffusion for 120 hours two distinct precipitin lines were observed, together with an outer faint hazy area of precipitin which was visible only adjacent to the well containing the undiluted antiserum.

The outermost precipitin line was visible to a titre of 1:8 in both the saline control and in the dilution in normal colon extract. The inner precipitin line persisted to a titre of $1: 32$ in both the control and test plates. The two precipitinlines showed the same effects of dilution in both plates, progressively approaching the outer well to the same extent (Fig. 3). Indeed, the precipitin patterns observed in the two plates were identical,

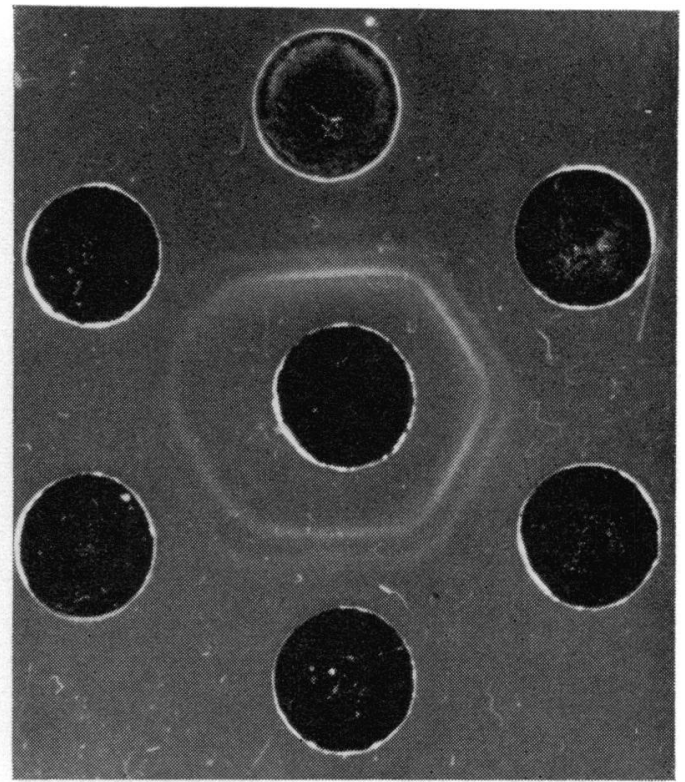

Fig. 3b.

Fig. 3. Immunodiffusion at 120 hours. Centre well contains perchlorate extract of colonic carcinoma. Peripheral wells (Fig. 3a) contain absorbed anti-CEA serum (cf Fig. 2) serially diluted in pooled normal colon extract: undiluted serum (well 1); 1:2 (well 2); 1:4 (well 3); 1:8 (well 4); 1:16 (well 5); and 1:32 (well 6). Figure $3 b$ shows immunodiffusion with same antigen but with the same antiserum serially diluted in buffered saline. Note that the two precipitin lines against the colon cancer are still present even after normal colon extract is mixed with the antiserum and that the effects of serial dilution in normal colon extract are identical to the effects of dilution with saline, confirming that precipitin lines observed do not contain antigens from normal colon. (The wells are numbered clockwise from top centre.) 
indicating that the addition of pooled normal colon antigens to the absorbed antiserum had no effect on the precipitin reactions other than that due to simple dilution. In the second type of experiment the absorbed antiserum was serially diluted in preparations of normal colon extract obtained from single individuals with colonic cancer. These diluted antisera were then tested by double diffusion for $\mathbf{4 0}$ hours against perchlorate extracts from the tumours of these same individuals. Again a control was set up with dilution of the antiserum in saline. Two precipitin lines persisting to a dilution of $1: 8$ were observed in both the saline control and in the experiment in which the antiserum was diluted with normal colon extract (Fig. 4).

The effect on the two precipitin lines of dilution of the antigen preparation was studied. Serial dilutions of the pooled antigen were made in buffered saline. These were diffused against the same amount of absorbed antiserum (Fig. 5). Under these conditions the precipitin line nearer the antigen wells persisted to a titre of $1: 16$ while the line further from the antigen was preserved to a titre of $1: 32$.

The absorbed antiserum was tested by double immunodiffusion against human fibrinogen and against extracts of mixed cultures of human colonic bacteria obtained both from the original carcinoma specimens and from other normal colon specimens. In all instances no precipitation reactions were observed.

Attempts were made to determine if the presence of two precipitin lines represented the presence of two distinct classes of immunoglobulin antibody, for example an IgG and an IgM. Accordingly preparations of rabbit IgG were made by passing absorbed anti-CEA serum through DEAE-cellulose columns in 0.01 $\mathrm{M}$

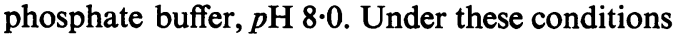
the rabbit immunoglobulin-G passes through the column and the other serum proteins are retained by the DEAE-cellulose (Martineau and Allen, 1970). When the absorbed rabbit anti-CEA serum was treated in this manner two peaks of material absorbing strongly at $280 \mathrm{nM}$ were observed in

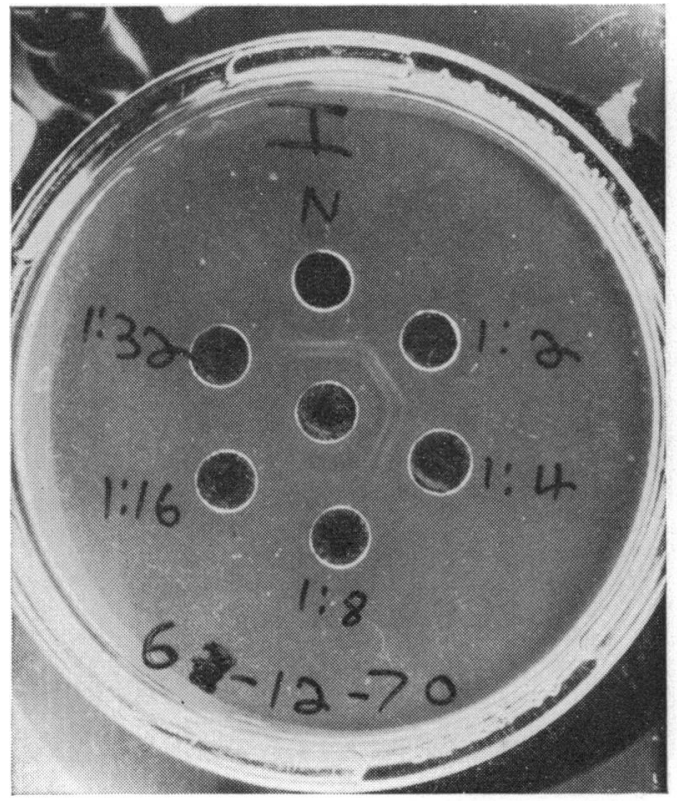

Fig. 4a.

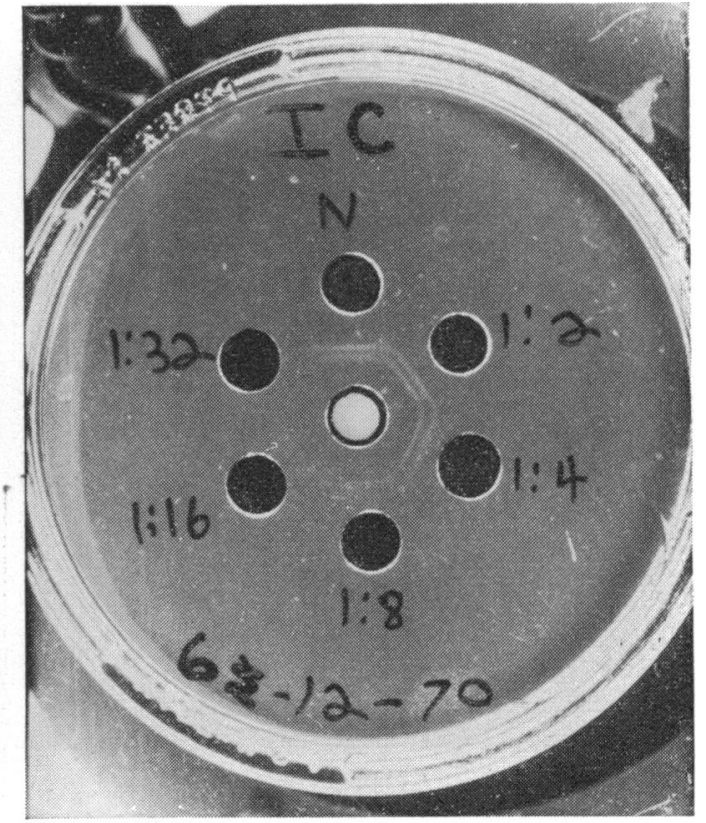

Fig. 4b.

Fig. 4. Forty-hour immunodiffusions. In both photographs the centre well contains perchlorate extract of colonic carcinoma from a single individual. Peripheral wells (Fig. 4a) contain absorbed anti-CEA serum serially diluted in perchlorate extract of normal colonic mucosa from the same individual. In Figure $4 b$ the dilutions are made in saline. Dilutions of antiserum are shown in the photographs $(N=$ undiluted antiserum $)$. The precipitin lines show the same effects of dilution in the two photographs regardless of whether the diluting agent is saline or normal colonic mucosal extract (cf Fig. 3). 


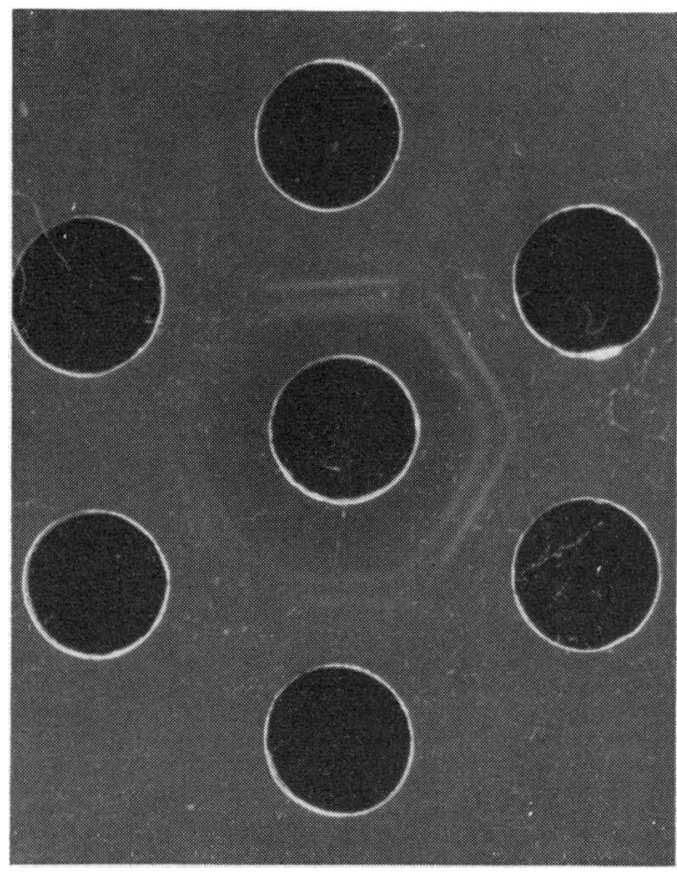

Fig. 5. Twenty-two-hour immunodiffusion. Centre well contains absorbed anti-CEA serum. Peripheral wells, clockwise from top centre, contain doubling dilutions of perchlorate extract of colonic carcinoma. Note two precipitin lines, the inner persisting to a dilution of 1:32 and the outer to a dilution of 1:16.

the column eluate (Fig. 6). From this behaviour both appeared to be IgG proteins and this was confirmed by immunoelectrophoresis (Fig. 7). Fractions 10, 11, and 12 containing the first peak were pooled and fractions 16 and 17 containing the second peak were mixed. After concentration these two peaks were tested by double diffusion. against the perchlorate extract of colonic carcinoma. Under these circumstances both peaks of IgG gave two precipitin lines similar to those observed with the whole absorbed antiserum.

An effort was made to determine if purification procedures applied to the colonic carcinoma extracts would result in the separation of two antigenic components. Accordingly, the perchlorate extract of colonic carcinoma was submitted to Pevikon electrophoresis as described above. The material obtained after Pevikon electrophoresis again showed two lines when tested against either the absorbed whole rabbit antiserum or against the preparations of absorbed rabbit IgG antiserum. After passage through Sephadex G200 CEA was detected in fractions 26

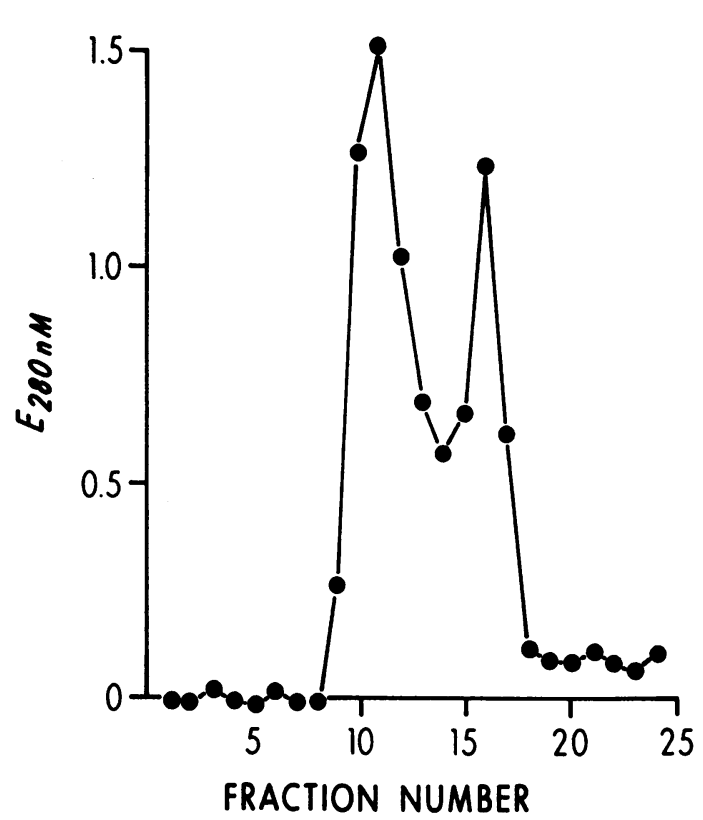

Fig. 6. DEAE-cellulose column chromatography of absorbed anti-CEA serum. Ordinate shows extinction at $280 \mathrm{nM}$ and abscissa the fraction of eluate obtained with $0.01 \mathrm{M}$ phosphate buffer, $\mathrm{pH} 8 \cdot 0$. Note that two peaks of material absorbing at $280 \mathrm{nM}$ are observed.

to 43; however, all of these gave two lines on immunodiffusion and there was no evidence of separation of the antigen into two distinct components (Fig. 8). Even after subsequent isoelectric focusing the CEA could not be separated into two distinct components.

When an absorbed antiserum prepared by $\mathrm{Dr}$ Gold was tested on immunodiffusion against the perchlorate extract of colonic carcinoma two lines of precipitation were again observed (Fig. 9). When the absorbed antiserum prepared in this laboratory was submitted to immunodiffusion for 24 hours against the perchlorate extract of colonic carcinoma alongside the antiserum prepared by Dr Gold a line of identity ws observed, indicating that the two antisera appeared to be recognizing at least one similar antigenic determinant (Fig. 10). On subsequent development of the plate for a longer time our serum gave the usual two preciptin lines, the outer of which showed a reaction of identity with the line produced by the serum from Dr Gold; the reactions were, however, too faint to photograph well and to date insufficient serum has been obtained to repeat the experiment and to 


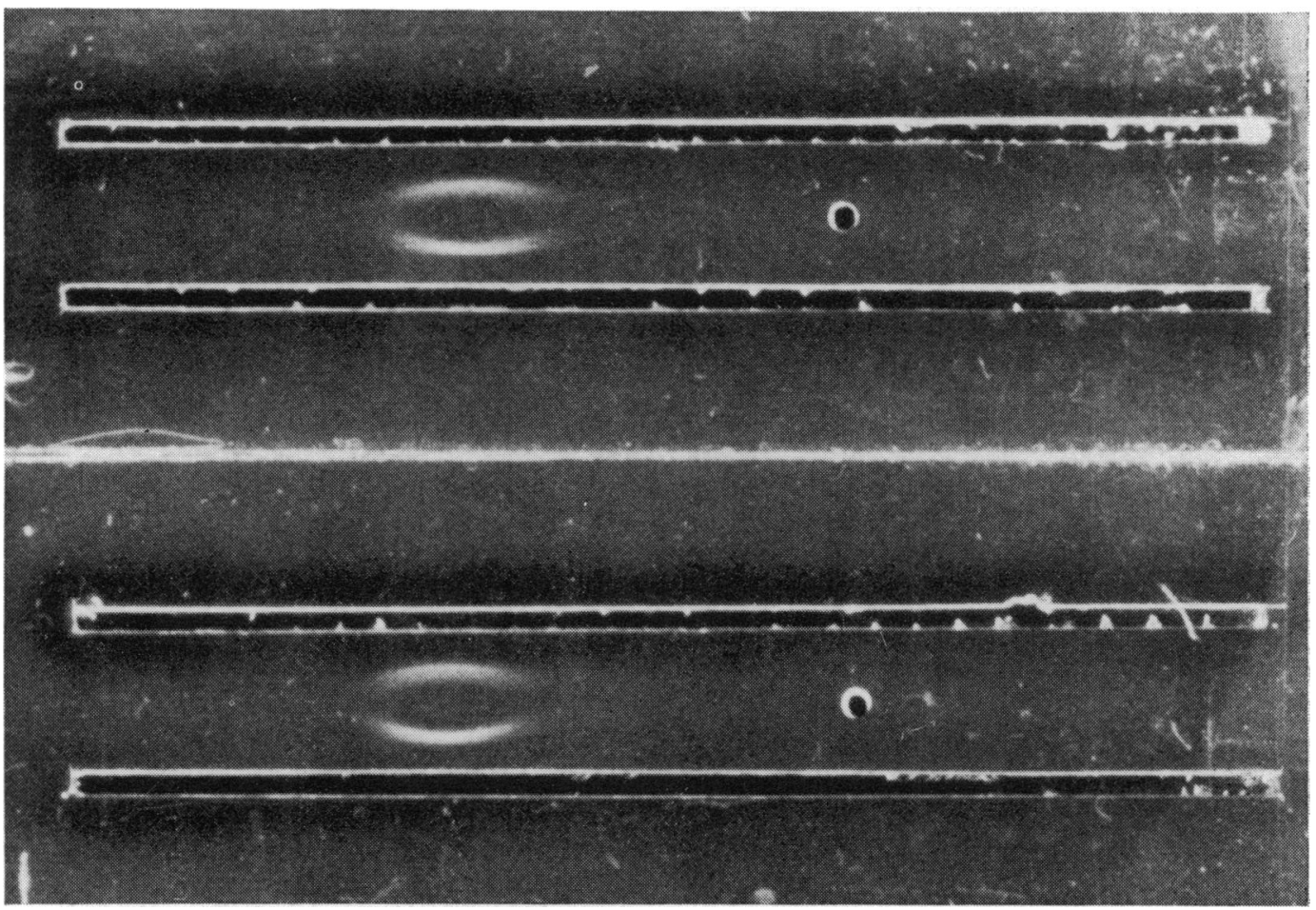

Fig. 7.

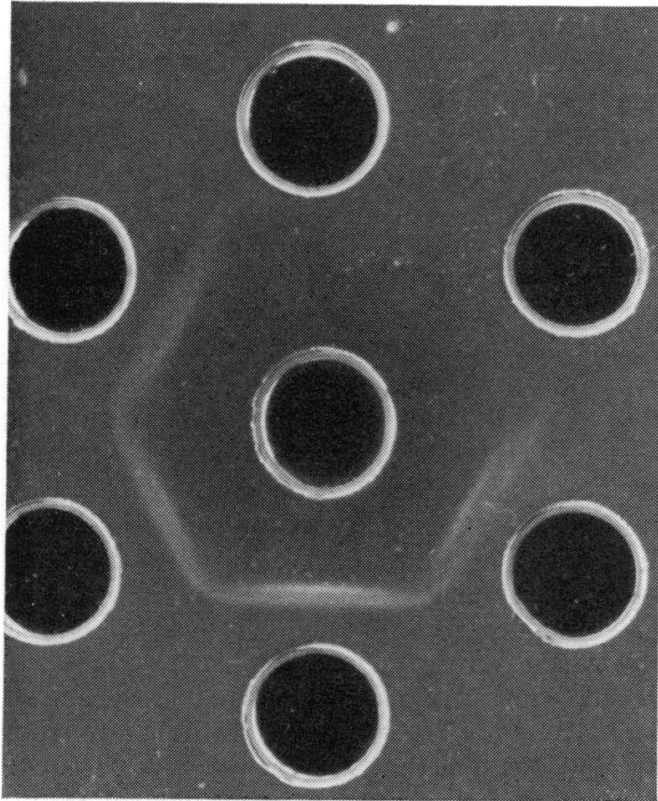

Fig. 8.
Fig. 7. Immunoelectrophoresis of fractions of rabbit IgG anti-CEA from DEAE-cellulose column of Figure 6. Slide 1 (bottom) contained pool of concentrated fractions 16 and 17 (second peak from DEAE column) and slide 2 (top) pooled fractions 10-12 (first peak from $D E A E$-column). The upper trough of each slide was filled with goat anti-rabbit-IgG serum and the lower trough of each with goat anti-whole-rabbit-serum. Note that both the two main peaks of material from the DEAE-cellulose column contain rabbit IgG though that in fractions 16 and 17 is slightly more mobile on electrophoresis than that in fractions 10-12.

Fig. 8. Forty-eight-hour immunodiffusion. Centre well contains absorbed antiserum against colon cancer antigens. Outer wells contain fractions from Sephadex G200 column loaded with partially purified antigens. Note that two precipitin lines are seen in fractions 26 , $27,28,29$, and 30. The topmost well, fraction 25 , shows no reaction against the antiserum. (The fractions are numbered clockwise from top centre.) 


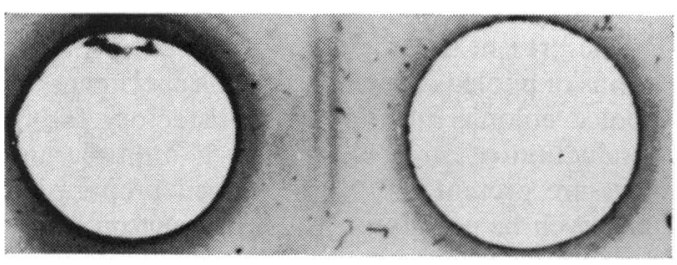

Fig. 9. Photograph of a stained preparation of double immunodiffusion plate. The left well contained absorbed antiserum prepared by Dr Gold in Montreal and the right well perchlorate extract of colonic carcinoma. Note that two precipitin lines are observed.

Fig. 10. Twenty-four-hour immunodiffusion. Lower left well contained electrofocused CEA. Top well contained absorbed anti-CEA serum made by Dr Gold and lower right well absorbed anti-CEA serum prepared in Rochester. Both sera give a precipitin line with the CEA preparation and the precipitation arcs fuse to give a reaction of identity.

determine if the two antisera will give two lines of identity when tested in this manner.

\section{Discussion}

These studies clearly demonstrated that carcinomata of the colon contain antigens which are not present in healthy adult colonic mucosa. Antisera were prepared against these materials in rabbits and the antibodies produced were not absorbed by the antigens in pooled normal human plasma, red cells, or pooled human colonic mucosa (Fig. 4). It was also shown that the antibodies did not react with colonic bacteria or with fibrinogen. A line of identity was demonstrated (Fig. 10) using antiserum prepared here and that produced by Gold in Montreal. These experiments therefore confirm the previous reports of Gold and Freedman (1965a and $b$ ) on the existence of colonic carcinoma antigens and indicate that the two different sera were recognizing at least one common antigen. The experiments reported here showed the presence of two distinct precipitin arcs when colonic carcinoma extracts were tested against absorbed antiserum prepared here and against antiserum prepared in Montreal, which was unfortunately available in insufficient quantity to demonstrate that both precipitin lines were identical.

The observation that both the antisera prepared here and that provided by Dr Gold gave two lines of precipitation on double diffusion against the perchlorate extract of colonic carcinoma leads

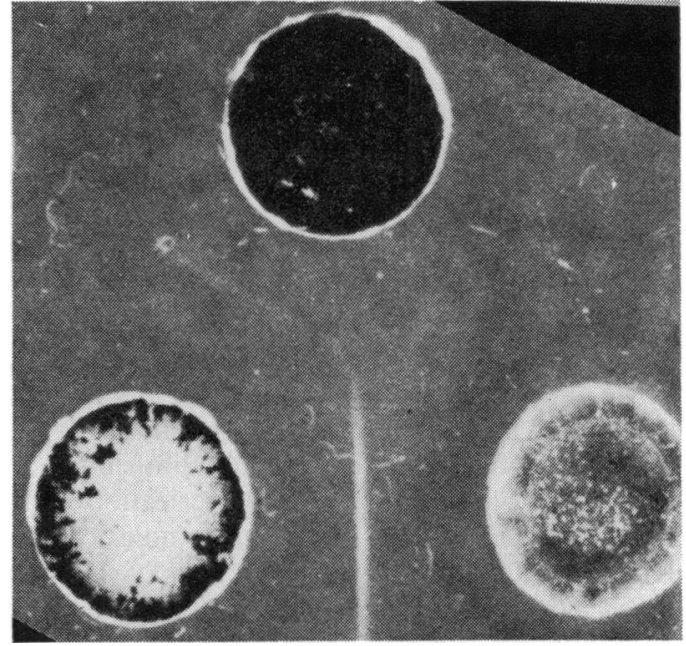

Fig. 10.

at once to an obvious conclusion, namely, that two distinct antigens were present in the perchlorate extract of colonic carcinoma. However, before this can be accepted as proven it is necessary to consider other possible explanations for this phenomenon, since reports of multiple banding in single antigen-antibody systems have appeared from time to time. Gleich and Allen (1965) found multiple precipitin lines when antibodies to a cellobiose-azoprotein conjugate were diffused against phloroglucinol triazophenyl- $\beta$-D-cellobioside, and Paul and Benacerraf (1966a) have described multiple banding in single antigenantibody systems when interaction with complement occurs. Dimerization of a single antigen may, at least theoretically, also give rise to two precipitation lines on immunodiffusion against a single antibody if the dimerization results in a 'burying' of some of the antigenic determinants which are 'uncovered' or detectable in the monomer. Thus an initial line of precipitation develops from interaction of monomer and antibody but the dimer is then able to diffuse through this zone only to react beyond it with further antibody. A similar effect might be observed with a single antigen reacting with an antiserum containing more than one type of antibody.

From the present experiments it is possible to discount a number of these explanations. Complement interaction cannot explain the two precipitin lines, since they were observed even in reactions with purified CEA and isolated rabbit IgG fractions which could have contained no comple- 
ment. Furthermore, although the antisera produced here showed the presence of two subclasses of IgG on DEAE-cellulose chromatography (Figs. 6 and 7) each of these when tested separately against perchlorate extract of colonic carcinoma gave two precipitin lines. Thus, although more than one type of antibody was present in the serum, this did not explain the multiple precipitations observed. The effects of dilution of the antigen preparation suggested that a concentration-dependent dimerization of a single antigen was not occurring (Fig. 5) although this cannot be established unequivocally solely on the basis of the results on immunodiffusion.

While the possibility of polymerization of a single antigen, as suggested by the studies of von Kleist and Burtin (1969), or reactions of the type described by Gleich and Allen (1965), cannot yet be completely excluded as the cause of the appearance of the two precipitin lines, it is certainly possible that the reactions reported here result from the presence of different antibodies reacting with two different antigens. What the differences between these antigens may be is far from clear. That one antigen may be a degradation product of the other produced factitiously during the process of extraction is, however, apparent. To judge from their similar behaviour on attempts to separate them by electrophoresis, Sephadex gel filtration and electrofocusing the two antigens would appear to be quite closely related, suggesting the possibility that they have a similar basic structure which is conjugated either to a different extent with a single type of active haptenic group (Paul and Benacerraf, 1966b) or with a number of different determinant groups.

Alternatively the two antigens may contain the same antigenic determinants but be of different molecular sizes. Such a situation has previously been observed to result in the production of multiple precipitin lines when one of the antigens is relatively small: 35,000 in the case of some dextrans (Finger, Kabat, Bezer, and Kidd, 1960). However, in the case of CEA if two antigens are present they must be of similar sizes since they were not separated by gel filtration on Sephadex G200. Although reactions of the type reported by Finger et al (1960) have not been described with such large antigens, one cannot as yet exclude the possibility that a single type of determinant is present. Further studies are clearly necessary to settle these questions. At least it appears that the two precipitin lines do not result from the use of pooled preparations of tumour tissue since two lines were clearly seen when extracts from single tumours were tested (Fig. 4).

The present investigations suggest that preparations of pooled colonic carcinoma specimens and pooled colonic mucosae are satisfactory for the production of antisera. Indeed, if multiple antigens are present the use of pooled preparations may even be preferable in the production of sera for routine diagnostic use.

We are most grateful to Dr Phil Gold of McGill University, Montreal, Quebec, Canada, for a gift of anti-CEA serum, to Dr Malcolm Dockerty of the Department of Surgical Pathology, Mayo Clinic and Foundation, Rochester, Minnesota, who supplied us with specimens of colonic adenocarcinoma, and to Dr Peter Z. Allen of the Department of Microbiology, University of Rochester, for most helpful discussions.

This work was supported by grant CA-09546 from the National Cancer Institute USPHS and by a grant from the Monroe County Cancer and Leukaemia Association.

\section{References}

Finger, I., Kabat, E. A., Bezer, A. E., and Kidd, A. (1960). Agar diffusion studies in the dextran-antidextran system. $J$. Immunol., 84, 227-230.

Flodin, P. (1962). Dextran Gels and their Applications in Gel Filtration. Pharmacia, Uppsala.

Gleich, G. J., and Allen, P. Z. (1965). Immunochemical studies on some immune systems involving $\beta(1,4)$ linked glucose. Immunochemistry, 2, 417-431.

Gold, P., and Freedman, S. O. (1965a). Demonstration of tumorspecific antigens in human colonic carcinomata by immunological tolerance and absorption techniques. J. exp. Med., 121, 439-462.

Gold, P., and Freedman, S. O. (1956b). Specific carcinoembryonic antigens of the human digestive system. J. exp. Med., 122, 467-481.

Kleist, S. von, and Burtin, P. (1969). Isolation of a fetal antigen from human colonic tumors. Cancer Res., 29, 1961-1964.

Lowry, O. H., Rosebrough, N. J., Farr, A. L., and Randall, R. J. (1951). Protein measurement with the Folin phenol reagent. J. biol. Chem., 193, 265-275.

Martineau, R., and Allen, P. A. (1970). Personal communication. Ouchterlony, O. (1949). Antigen-antibody reactions in gels and the practical application of this phenomenon in the laboratory diagnosis of diphtheria. Thesis, Karolinska Institutet, Stockholm.

Paul, W. E., and Benacerraf, B. (1966a). Problems encountered in double diffusion analysis in agar of hapten specific immune systems. I. Complement dependent precipitation. $J$. Immunol., 95, 1067-1073.

Paul, W. E., and Benacerraf, B. (1966b). Problems encountered in double diffusion analysis in agar of hapten specific immune systems. II. The effect of the relative solubility of the immune complexes formed by cross-reacting systems. $J$. Immunol., 95, 1074-1079.

Thomson, D. M. P., Krupey, J., Freedman, S. O., and Gold, P. (1969). The radioimmunoassay of circulating carcinoembryonic antigen of the human digestive system. Proc. nat. Acad. Sci. (Wash.), 64, 161-170.

Yachi, A., Matsuura, Y., Carpentier, C. M., and Hyde, L. (1968). Immunochemical studies on human lung cancer. Antigens soluble in $50 \%$ saturated ammonium sulphate. J. nat. Cancer Inst., 40, 663-682. 